\title{
How to Construct Effective Consultation System for S\&T Decision-making
}

\author{
Zijun Tang ${ }^{1, a}$ \\ ${ }^{1}$ Office of Scientific Research Management Jishou University Jishou Hunan China
}

\begin{abstract}
With the development of a new round of science and technology (S\&T) revolution and industrial transformation in the world, the complexity of S\&T decision-making is increasing. It not only needs the comprehensive participation of scientific, technological, economic, educational and other social factors but also an effective consultation system to guarantee. To build an effective consultation system for S\&T decision-making, a lot of measures can be taken, such as establishing the system of the policy and regulation, perfecting the multi-mode operation system, constructing the support system of talent team, developing of multi-channel financing system, optimizing the system of social public participation and strengthening the system of interactive international cooperation.
\end{abstract}

\section{Introduction}

The consultation system of S\&T decision-making is the inevitable result of scientific and technological progress and social development, and also the inherent requirement for government decision-making. As a result of the new round of scientific and technological revolution and industrial transformation, the complexity of science and technology strategy and policy making is increasing, and the comprehensive participation of scientific, technological, economic, educational and other social factors and various think tanks is needed. China also attaches great importance to the construction of the consultation system of S\&T decision-making. In January 2015, The Opinions on Strengthening the Construction of a New Think Tank with Chinese Characteristics, issued by the Office of the CPC Central Committee and General Office of State Council, emphasized that "the consultation system of the decision-making is an important part of the construction of socialist democratic politics in China, and the new think tank with Chinese characteristics is an important content of the modernization of the national governance system and also an important part of the country's soft power "[1]. In September 2015, the Office of the CPC Central Committee and General Office of State Council issued The Implementation Plan for Deepening the Reform of the Scientific and Technological System, which called for "the establishment of a national consultation mechanism of innovation and S\&T decisionmaking, the development of a good scientific and technological community and think tank to support innovation and S\&T decision-making, the establishment of a national advisory committee of S\&T decision-making" [2].On the May 30, 2016, General Secretary Xi Jinping stressed in his important speech Striving to Build a World Science and Technology Power, "We should speed up the establishment of mechanism of S\&T decision-making to support administrative decision-making, strengthen the consultation system of S\&T decision-making, and build a high level science and technology think tank to accelerate the institutionalization of major scientific and technological decisions "[3] February 2017, the CPC Central Committee passed the Plan of the Construction Program of National Consultation System of $S \& T$ Decision-making, pointed out to build a national consultation system and a think tank at the highest level of S\&T decision-making. The Plan is a re-promotion of China's current consultation mechanism of S\&T decisionmaking, marking the China's consultation of S\&T decision-making is on the process of institutionalization and systematization. There are a lot of measures can be taken to construct the effective consultation system for S\&T decision-making in China.

\section{Improving the policy and regulation guarantee system}

The smooth development of consultation of S\&T decisionmaking is guaranteed by sound policies and regulations. Developed countries all regard the construction of perfect legal system as the key to promote the consultation of decision-making. The supporting policies and regulations of consultation of S\&T decision-making in China are in the initial stage and need to be strengthened and improved in the following four aspects. The first is to incorporate consultation into the legal procedures for major decisionmaking of government departments, protect the legal status

a Corresponding author: zijuntang@163.com 
of consulting bodies through relevant laws and regulations, and specify their power and responsibility relationship, expert selection, organizational structure and operation mode; Secondly, the status and role of different types of consultation bodies in decision-making should be clarified through legislation. In particular, the consultation procedures should be standardized and designed through specific legal provisions to ensure the relative independence of consultation bodies. Meanwhile, corresponding incentive measures should be formulated according to different consultation situations; Thirdly, establish the application and feedback system of important S\&T decision-making consultation achievements, and strengthen the legal regulation of the formation, release and use of consultation reports. Fourthly, establish a supervision system and restriction mechanism for S\&T decision-making consultation, and a public disclosure and hearing system for major decision-making matters, ensure the openness of all links and procedures of decisionmaking consultation, protect the right of supervision and information of the public, and promote the openness, transparency and fairness of decision-making consultation activities.

\section{Perfecting the multi-mode operation system}

It is a common direction for the development of consultation system of S\&T decision-making in various countries to construct different and complementary consultation systems at different levels and of various types. It is a common practice in the international community to set up a committee with members spanning all fields, controlling the number of members and highlighting their representativeness. China has already established the construction plan of the national science and technology advisory committee, and it is necessary to further improve the operation mode of the institution. At the horizontal level, to promote the coordinated development of official advisory bodies and parastatal and civil advisory bodies, encourage the Government to purchase consultation services of S\&T decision-making, support the development of market-oriented decisionmaking advisory bodies through corresponding policy measures, strengthen their financial support, and enhance the status and influence of civil decision-making advisory bodies, finally form a useful supplement to the official advisory body, make China's consultation of S\&T decision-making to the direction of specialization. At the vertical level, there is a need for a multi-tiered and complementary advisory body layout, based on the hierarchical distribution of existing decision-making advisory bodies, from the national level, the sectoral level to the grass-roots level and social institutions. For example, in the case of high-level consultation on major political and diplomatic decisions, the national advisory committee on science and technology may make advisory recommendations on such decisions. When it comes to decision-making in the social and public fields, appropriate decision-making consultation bodies may be set up according to the local characteristics and actual conditions of various departments, institutions and regions. The perfect operation mechanism is the premise to ensure the decision-making level to grasp the relevant policy information accurately, timely and systematically, provide objective and reasonable scientific support for decisionmaking, and is also the key to test its effectiveness.

\section{Constructing the support system of talent team}

The high-quality S\&T decision-making consultation needs the novelty, reliability and policy relevance of knowledge, which will inevitably put forward special requirements for the construction of talent team in decision-making consultation bodies. According to the present situation of decision-making consultation in China, it should be firstly focused on cultivating interdisciplinary knowledge talents and strengthening the ability of strategic research. In order to better cope with increasingly complex decision-making problems and enhance the effectiveness of decisionmaking suggestions, it is necessary to cultivate research talents with multi-disciplinary complementarity and crossdisciplinary advantages, and pay attention to the selection and training of talents in terms of professional depth, disciplinary breadth, scientific height and social perspective. Secondly, the evaluation and incentive mechanism of S\&T decision consultation talents should be constructed through targeted measures. It will be formulated that unified and standardized evaluation standards for the employment, professional title assessment, moral character and ability and social contribution of talents, and take the social impact of the consultation recommendations as the core assessment indicators. At the same time, by encouraging original ideas, respect for intellectual property rights, the establishment of talent program projects and other methods, to stimulate the healthy development of consulting talent team, to provide sustainable talent support for decision-making consultation, enhance the capacity and level of S\&T decision-making advisory bodies. Thirdly, it should be pay more attention to cultivating and promoting the professional ethics of decision-making consultation talents. In the selection of advisory members and experts, social responsibility and academic ethics should be the basic standards, and the professionalism of responsible consultation should be actively promoted so that S\&T decision-making consultation can truly win the affirmation and trust of the society.

\section{Developing multi-channel financing system}

A certain amount of financial support is a necessary condition for the normal operation of decision-making advisory bodies. The advisory bodies of developed countries are mainly funded by government grants, corporate grants, private donations and dues. At present, China mainly supports the operation of decision-making advisory bodies through the way of government financial allocation, while the proportion of enterprises and private 
financial support needs to be further improved. Therefore, the management system of decision-making consultation funds should be reformed, change the homogenization mode of financing, encourage enterprises to invest in the establishment of advisory bodies and promote their market-oriented operation. At the same time, civil and individual donations, etc., should also be given some recognition and support, in order to further enrich the funding sources of decision-making advisory bodies. Of course, whether it is from the public finances or corporate sponsorship and social donations, there should be transparent and open management of financial intervention in order to prevent the possible existence of "undercover operation" through financial support, affecting or shaping the advisory opinions. Then the advisory bodies are not disturbed by some kind of "external" factors and can objectively provide independent advice on a fair attitude.

\section{Optimizing the system of public participation in society.}

Many decision-making problems in social development are often closely related to the public interest, and actively promoting public participation is of great significance to improve the sound consultation system of S\&T decisionmaking. Firstly, through the systematic formulation of system rules, introducing orderly and effectively public participation in the progress of decision-making advisory activities can help to jointly promote the formation of decision-making solutions, and also can make the decision-making advisory bodies widely accept public supervision, better promote the openness and transparency of the consultation process; Secondly, the Government should strengthen the guiding role of public participation in decision-making, speed up the institutionalization of public participation, create a good institutional environment, make public participation an integral part of the decision-making consultation process, so that the public really enjoy the right to participate in decisionmaking consultation, and have a practical role and influence in the process of decision-making consultation; Thirdly, a multi-subject decision-making consultation platform including government, S\&T decision-making advisory bodies and the public should be further built, so as to smooth out the information communication channels between the government and the society.

\section{Strengthening the system of interactive international cooperation}

In the context of globalization, international influence is one of the important goals pursued by S\&T decisionmaking advisory bodies, for which most national decisionmaking advisory bodies adopt open policies and conduct international research, operation and exchange in order to obtain a voice on international issues. In order to meet the requirements of the new era, China should further promote the international development of S\&T decision-making consultation, and promote the competitive platform of intellectual products to the international market. Firstly, carry out cooperative research and exchange dialogue with foreign S\&T decision-making advisory bodies, draw on their organizational methods, operating models and discourse paradigms, and selectively integrate them into the construction of our own advisory bodies in accordance with the actual situation in China. Secondly, expand the voice of domestic decision-making advisory bodies in the international arena, strive to "lead" in some global issues and China issues that arouse world concern, and build a group of decision-making advisory bodies with international influence. Thirdly, cultivate a team of consulting talents with critical spirit and innovative consciousness, international discourse ability and competitiveness, launch original research achievements with the value of the times and global consciousness, and improve the academic reputation in the international arena. The last is to actively promote the establishment of S\&T decision-making advisory branches abroad, as a means of establishing effective international cooperative relations for the exchange platform, and to expand the international recognition and influence of advisory bodies through advisory activities on China's foreign policy.

\section{Acknowledgement}

This paper was financially supported by the project of Science and Technology Plan of Xiangxi Autonomous Prefecture, "The Research on the Mechanism of University -affiliated think tanks participating in Local Science and Technology Innovation Decision-making consultation" (No.2018SF5015)

\section{References}

1. The Executive Office of the CPC Central Committee and General Office. On strengthening Chinese characteristics Views on the construction of a new think tank. [2016-09-30]. http://www.gov.cn/Xinwen/201501/20/content 2807 126.htm

2. The Executive Office of the CPC Central Committee and General Office. Deepening the implementation of scientific and technological system reform case. [2016-09-30]. http://www.gov.cn/guowuyuan/2015/09/24/Content 2938314.htm

3. Xi Jinping. Strive to build a world science and technology power. People's Daily, 6(2016). 